\title{
DETERMINATION OF EQUIVALENT SIZE OF MICROBIAL CELLS FROM THEIR VELOCITIES IN HINDERED SETTLING
}

\author{
SHUICHI AIBA, SUMI KITAI and HARUO HEIMA \\ Institute of Applied Microbiology, University of Tokyo, Tokyo \\ Received July 3, 1964
}

The proper evaluation of "equivalent" size of microbial cells seems to be significant for the analysis of mass and heat transfer of various separation processes in the fermentation industry. The term, "equivalent" originated from the fact that the cells concerned are assumed to be spherical in shape, primarily in terms of their dynamical behavior in liquid media.

As prohibitive as it may sound, especially for fungi in which a network of fibrous mycelia is formed during the course of fermentation, the introduction of a concept of equivalent size will, nevertheless, be of importance. For example, the transfer rate of a specific substance to/from the network can be discussed in general terms only if the area which participates in the transfer can be estimated quantitatively. For this sort of evaluation, the "equivalent" concept which describes the microbial suspension on an average and in situ is considered to be helpful as the first approximation. Additionally, the phenomena, in which the mycelial network disintegrates into fragments due to various reasons occur sometimes during the fermentation. The concept mentioned above will also be of use for studying a degree of such disintegration.

Furthermore, with reference to simpler shapes of bacteria or yeasts, there may arise a necessity of judging whether or not the cells in question are flocculated and if flocculated, of knowing the degree of flocculation. The "equivalent" size, if properly determined, will be significant for meeting this sort of necessity.

The principal objective of this report is to demonstrate experimentally the possibility of determining equivalent size of representative cells - yeast, bacterium and Actinomycetes-from the velocities in hindered settling without resorting to microscopic examination. The equivalent size of an activated sludge from a municipal sewage treatment plant in Tokyo was also studied.

The demonstration described here was made possible by using the empirical correlation which was reported previously on the concentration of fine particles and their velocities in hindered settling (1). 


\section{MATERIALS AND METHODS}

The cells of yeast and bacterium used were grown in shaking cultures $\left(30^{\circ}, 48 \mathrm{hr}\right)$, while those of Actinomyces used were cultivated at $27^{\circ}$ in the same type of culture prior to each experiment. After separation by centrifugation, the cells were rinsed once with buffer solution and resuspended in the buffer. The solution volume was changed to varying degrees from run to run in each series of sedimentation experiments in order to ensure various concentrations of the cells in suspension. The compositions of culture medium and buffer solution used in each case are summarized in Table 1. The activated sludge examined was sampled each

Table 1. Experimental conditions.

\begin{tabular}{|c|c|c|c|c|c|}
\hline Strain & $\begin{array}{l}\text { Culture } \\
\text { medium }\end{array}$ & $\begin{array}{l}\text { Suspension } \\
\text { medium }\end{array}$ & $\begin{array}{c}\text { Glass vessel } \\
\text { (approx. height } \\
\text { of initial } \\
\text { suspension), mm }\end{array}$ & $\begin{array}{l}\text { Room } \\
\text { temp }\end{array}$ & $\begin{array}{l}\text { Reference } \\
\text { and period }\end{array}$ \\
\hline $\begin{array}{l}\text { Saccharomyces } \\
\text { cerevisiae }\end{array}$ & $\begin{array}{l}\text { meat extract } \\
0.3 \% \\
\text { yeast extract } \\
0.3 \% \\
\text { peptone } 0.5 \% \\
\text { glucose } 1 \% \\
\text { pH }=5.0\end{array}$ & $\begin{array}{l}0.05-\mathrm{M} \\
\mathrm{KH}{ }_{2} \mathrm{PO}_{4}, \\
\mathrm{pH}=5.0\end{array}$ & $\begin{array}{c}15 \phi \times 200 \\
(130)\end{array}$ & $11 \sim 17$ & $\begin{array}{l}\text { Gravitational } \\
\text { settling } \\
\text { March, } 1962\end{array}$ \\
\hline $\begin{array}{l}\text { Serratia } \\
\text { marcescens }\end{array}$ & $\begin{array}{l}\text { meat extract } \\
1 \%\end{array}$ & $\begin{array}{c}0.1 \mathrm{~N}-\mathrm{KH}_{2} \mathrm{PO}_{4} \\
(4.536 \mathrm{~g} / \mathrm{l}) \\
+0.1 \mathrm{~N} \\
-\mathrm{Na}_{2} \mathrm{HPO}_{4}\end{array}$ & $\begin{array}{c}12 \phi \times 105 \\
(80)\end{array}$ & $33 \sim 35$ & $\begin{array}{l}\text { Centrifugal } \\
\text { settling } \\
\text { July } \sim \text { Aug., } \\
1962\end{array}$ \\
\hline $\begin{array}{l}\text { Streptomyces } \\
\text { griseus }\end{array}$ & $\begin{array}{l}\text { glucose } 2 \% \\
\mathrm{NaCl} 0.2 \% \\
\mathrm{pH}=7.0\end{array}$ & $\begin{array}{c}\text { Vol. ratio }=1: 2 \\
\text { (Michaelis } \\
\text { buffer sol.) } \\
\text { pH }=7.0\end{array}$ & $\begin{array}{c}60 \phi \times 400 \\
\quad(150)\end{array}$ & $23 \sim 25$ & $\begin{array}{c}\text { Gravitational } \\
\text { settling } \\
\text { April June, } \\
1962\end{array}$ \\
\hline $\begin{array}{l}\text { Activated } \\
\text { sludge }\end{array}$ & & & $\begin{array}{c}60 \phi \times 400 \\
(350)\end{array}$ & $10 \sim 12$ & $\begin{array}{c}\text { Gravitational } \\
\text { settling } \\
\text { Dec., } 1961\end{array}$ \\
\hline
\end{tabular}

time from the return sludge in the Mikawashima Municipal Sewage Treatment Plant, Tokyo.

The suspension was transferred to a graduated cylindrical vessel of glass to each pre-determined level (see also Table 1) and allowed to settle at room temperature in respective fields.

Before proceeding to describe the procedure for sedimentation experiments, it seems to be necessary to elucidate the means which was adopted, primarily for simplicity, in determining the cell concentration (volume fraction) in each suspension.

Determination of volume fraction of the cells in each suspension.

1. Saccharomyces cerevisiae

A part of the suspension was transferred to a graduated tubiform 
glass vessel, $10 \mathrm{~cm}^{3}$ in volume. Then, the vessel was centrifuged at about $700 \times \mathrm{g}$ for $10 \mathrm{~min}$. The ratio of the sediment volume to that of the suspension defined $c$ in this case.

\section{Serratia marcescens}

A portion of the suspension was transferred to a cylindrical vessel of acrylic resin (graduated and transparent: $9 \mathrm{~mm} \times 98 \mathrm{~mm} \times 5 \mathrm{~mm}$ in internal diameter, height and wall thickness, respectively) and allowed to settle in a centrifugal field at about $10^{4} \times \mathrm{g}$ for $15 \mathrm{~min}$. Since the above vessel which was inserted into a conical rotor of fixed orientation was rotated, tilted to the plane of rotation, the interface of the suspension which was observed after the centrifugation was at an angle to the horizontal plane. In order to remedy this situation, the vessel was recentrifuged at about $1,700 \times \mathrm{g}$ for $5 \mathrm{~min}$. The centrifuge which was used for the latter centrifugation was equipped with a couple of metallic receivers, into one of which the vessel was inserted. The tubiform receivers were suspended freely along the rotor circumference and therefore were rotated in a horizontal plane due to the centrifugal force. The sediment volume obtained after the successive centrifugation was used to determine the value of $c$ in the case of Serratia marcescens.

3. Streptomyces griseus

The suspension which was transferred to the cylindrical glass vessel in Table 1 was continued to settle for about $72 \mathrm{hr}$ at room temperature in each experiment of sedimentation. The volume fraction $c$ was evaluated from the sediment volume obtained $72 \mathrm{hr}$ after the start of experiment, since the sediment volume in each suspension remained almost constant after a certain period of time. So far as this series of experiments was concerned, any degree of degradation or disintegration of the mycelia was not observed visually as well as microscopically even after settling for about 3 days, at room temperature $\left(23-25^{\circ}\right)$.

4. Activated sludge

The sediment volume obtained after $24 \mathrm{hr}$ of gravitational settling was used to define the value of $c$. This sort of arbitrary definition is based on the experimental fact that the interface of sludge (suspension) came to a standstill during a period of $24 \mathrm{hr}$. This procedure of defining the sediment volume to compute the value of $c$ does not seem to be generally applicable, since the sludge flocs may disintegrate or be modified in shape spontaneously during the long period of $24 \mathrm{hr}$. However, since the experiment with the activated sludge was conducted at lower temperatures $\left(10-12^{\circ}\right)$, the errors which may be associated with the phenomenon of aging referred to above were assumed to be negligible.

Determination of settling velocities.

1. Gravitational field: The location of the interface of each suspension was measured directly at definite time intervals. The experimental data on the rate of subsidence of interface were obtained from linear relationships 
between the distance traveled by the interface and the time elapsed after the start of each experiment. In other words, the data adopted here are those of constant velocities in hindered settling.

2. Centrifugal field: The cells of Serratia marcescens suspended in the glass vessel of Table 1 were subjected to centrifugation repeatedly in each experiment. The centrifuge which was used in this experiment for determining the velocity of settling was the same as that mentioned earlier. Namely, the glass vessel was rotated in a plane of rotation and the centrifugal force perpendicular to the interface was imposed on the suspension during the rotation. In conducting the experiment, centrifugation was suspended temporarily every 10 to $30 \mathrm{~min}$ to measure the location of the interface. Since the interface position changed during each period of centrifugation, the effective magnitude of centrifugal acceleration imposed on the cells was calculated using an arithmetical average of the initial and final readings of the interface corrected from the axis of rotation. The angular velocity of the centrifuge was measured with a tachometer. The distance, of the order of several millimeters, traveled by the interface during each period of intermittent centrifugation was divided by the period of each centrifugation to obtain an average settling velocity of the cells.

The period of each centrifugation (10 to $30 \mathrm{~min}$, referred to earlier) covers exclusively that of a definite angular velocity of the centrifuge without including the periods needed to accelerate and decelerate the glass vessel which was inserted into the rotor of the centrifuge. The experimental errors which might have been caused from the inertia of the rotor were assumed to be negligible due to the following reasons. The time required to raise the rotor from zero to a definite value $(3,700$ r.p.m. in this experiment) was about $30 \mathrm{sec}$, while that needed for it to come to a complete stop after being switched off was about $1 \frac{1}{2}$ min. However, it was ascertained from the preliminary experiment that the cells in suspension - the concentration of the cells being of the same range as in this series of experiments-did not settle to any measurable degree during about half an hour when the centrifuge was rotated at 2,000 r.p.m.

Therefore, the ambiguous effect which may be anticipated during the transient periods of rotation (about $2 \mathrm{~min}$ in total in this case of the centrifuge) on calculating the settling velocity of the cells was considered negligible.

However, the temperature rise of the suspension originated from the repeated centrifugation could not be neglected. The effect of the temperature rise on the final result of equivalent size of the cells will be discussed later. The interfacial level of the suspension was not disturbed to any extent by the intermittent centrifugation.

Determination of densities $\left(\rho_{y}, \rho_{m}\right)$ and viscosity ( $\left.\mu^{\prime}\right)$. Eq. (1) was used to determine the values of $\rho_{y}$, the densities of respective cells. 


$$
\rho_{y}=\frac{\rho_{c}-(1-c) \rho_{m}}{c}
$$

Prior to the determination of $\rho_{y}$, the values of $\rho_{c}$ and $\rho_{m}$, the densities of each suspension and liquid medium, were measured with picnometers (5c.c.) at room temperature in parallel with the sedimentation experiments.

Viscosities of the liquid media used were also measured with the Ostwald viscometer at room temperature. When the temperature rise of media above room temperature could not be neglected due to the repeated contrifugation, the viscosities of the media were corrected properly as will be shown later. Furthermore, microscopic photographs were taken to measure the size of respective cells as far as it was possible.

\section{RESULTS AND DISCUSSIONS}

Equations which were adopted to compute the equivalent size $d_{e}$ from the subsidence rate data $v$ of interface are in the order described below. First, the settling velocity $V$ of a swarm of particles (cells) was calculated from Eq. (2).

$$
V=\frac{v}{1-c}
$$

Secondly, the settling velocity $V_{0}$ of a single particle (cell) in an infinite medium was calculated from Eq. (3). The values of $\alpha$ in the equation were determined with reference to the published correlation between $\alpha$ and $c$ (1). Practical data $(\alpha)$ will be described later from case to case.

$$
\begin{aligned}
& V_{0}=V\left(1+\alpha c^{1 / 3}\right), \\
& \alpha=\beta^{\prime}+\beta^{\prime \prime} f(c)
\end{aligned}
$$

provided: $\beta^{\prime}, \beta^{\prime \prime}$ empirical constants.

Lastly, the value of $d_{e}$ was determined from Eq. (4), in which the value of $Z$ is equal to unity in the case of gravitational settling.

$$
d_{e}=\sqrt{\frac{18 V_{0} \cdot \mu^{\prime}}{Z \cdot g \cdot\left(\rho_{y}-\rho_{m}\right)}}
$$

where

$\mu^{\prime}=$ viscosity of medium

$Z=$ ratio of acceleration in centrifugal field to that due to gravity

$$
\text { (=centrifugal effect) }
$$

\section{Saccharomyces cerevisiae}

An example of the experimental results obtained is shown in Fig. 1, the ordinate of which is the distance $m_{i}$ traveled by the interface, while the abscissa represents the time $t$ after the start of each run. The values of $v$ which were determined from each set of data points in the figure with the method of least squares (1) are shown in Table 2. The experimental 


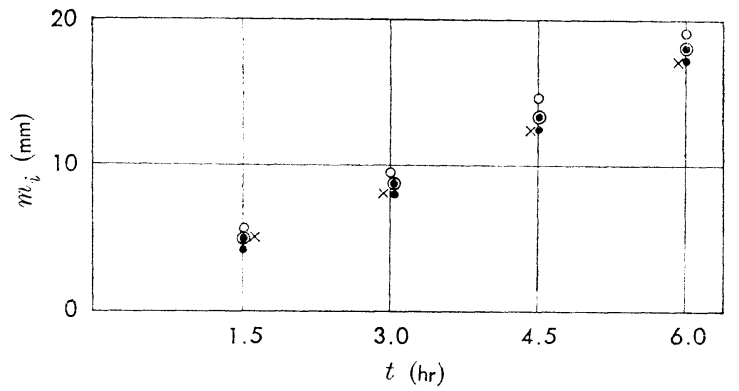

\begin{tabular}{|c|c|c|}
\hline Symbol & $C$ & Run No. \\
\hline 0 & 0.0164 & $3 \cdot 16 \cdot 1$ \\
\hline 0 & 0.0246 & $3 \cdot 16 \cdot 2$ \\
\hline$\cdot$ & 0.0410 & $3 \cdot 16 \cdot 3$ \\
\hline$x$ & 0.0574 & $3 \cdot 16 \cdot 4$ \\
\hline
\end{tabular}

Fig. 1. Rate of subsidence of interface (suspension of Saccharomyces cerevisiae).

Table 2. Experimental result and calculation.

(Saccharomyces cerevisiae)

\begin{tabular}{|c|c|c|c|c|c|c|c|c|c|c|}
\hline \multirow{3}{*}{ Run No. } & \multirow{3}{*}{$c$} & \multirow{3}{*}{$v(\mathrm{~mm} / \mathrm{hr})$} & \multirow{3}{*}{$\mathrm{V}(\mathrm{cm} / \mathrm{sec})$} & \multirow{2}{*}{\multicolumn{3}{|c|}{$d_{e}$ (microns) }} & \multicolumn{4}{|c|}{$\overline{d_{e}}$ (microns) } \\
\hline & & & & & & & \multicolumn{3}{|c|}{ Calculated } & \multirow{2}{*}{$\begin{array}{l}\text { Observed } \\
\text { microsco- } \\
\text { pically }\end{array}$} \\
\hline & & & & $\alpha=0$ & $\alpha=1$ & $\alpha=2$ & $\alpha=0$ & $\alpha=1$ & $\alpha=2$ & \\
\hline $3 \cdot 14 \cdot 1$ & 0.0080 & 3.53 & $0.99 \times 10^{-4}$ & 4.8 & 5.2 & 5.7 & \multirow{15}{*}{$\begin{array}{l}\ddot{1} \\
\dot{0} \\
+1 \\
\ddot{+}\end{array}$} & \multirow{15}{*}{$\begin{array}{l}\dddot{1} \\
\dot{0} \\
+1 \\
0 \\
\dot{0}\end{array}$} & \multirow{15}{*}{$\begin{array}{l}v \\
0 \\
+1 \\
10 \\
10\end{array}$} & \multirow{15}{*}{$\begin{array}{l}0 \\
0 \\
+1 \\
10 \\
10\end{array}$} \\
\hline $3 \cdot 14 \cdot 2$ & 0.0240 & 3.07 & $0.88 \times 10^{-4}$ & 4.5 & 5.1 & 5.7 & & & & \\
\hline $3 \cdot 14 \cdot 3$ & 0.0400 & 2.97 & $0.86 \times 10^{-4}$ & 4.5 & 5.2 & 5.8 & & & & \\
\hline $3 \cdot 15 \cdot 1$ & 0.0195 & 2.70 & $0.76 \times 10^{-4}$ & 4.2 & 4.7 & 5.2 & & & & \\
\hline $3 \cdot 15 \cdot 2$ & 0.0390 & 2.67 & $0.77 \times 10^{-4}$ & 4.2 & 4.9 & 5.5 & & & & \\
\hline $3 \cdot 15 \cdot 3$ & 0.0585 & 2.57 & $0.76 \times 10^{-4}$ & 4.2 & 4.9 & 5.6 & & & & \\
\hline $3 \cdot 15 \cdot 4$ & 0.0780 & 2.63 & $0.79 \times 10^{-4}$ & 4.3 & 5.1 & 5.8 & & & & \\
\hline $3 \cdot 16 \cdot 1$ & 0.0164 & 3.03 & $0.86 \times 10^{-4}$ & 4.5 & 5.0 & 5.5 & & & & \\
\hline $3 \cdot 16 \cdot 2$ & 0.0246 & 2.90 & $0.83 \times 10^{-4}$ & 4.4 & 5.0 & 5.5 & & & & \\
\hline $3 \cdot 16 \cdot 3$ & 0.0410 & 2.87 & $0.83 \times 10^{-4}$ & 4.4 & 5.1 & 5.7 & & & & \\
\hline $3 \cdot 16 \cdot 4$ & 0.0574 & 2.67 & $0.79 \times 10^{-4}$ & 4.3 & 5.0 & 5.7 & & & & \\
\hline $3 \cdot 19 \cdot 1$ & 0.0052 & 3.00 & $0.84 \times 10^{-4}$ & 4.4 & 4.8 & 5.1 & & & & \\
\hline $3 \cdot 19 \cdot 2$ & 0.0104 & 2.93 & $0.82 \times 10^{-4}$ & 4.3 & 4.8 & 5.2 & & & & \\
\hline $3 \cdot 19 \cdot 3$ & 0.0156 & 2.80 & $0.79 \times 10^{-4}$ & 4.3 & 4.8 & 5.2 & & & & \\
\hline $3 \cdot 19 \cdot 4$ & 0.0195 & 2.80 & $0.79 \times 10^{-4}$ & 4.3 & 4.8 & 5.3 & & & & \\
\hline
\end{tabular}

$\rho_{y}=1.09 \mathrm{~g} / \mathrm{cm}^{3}( \pm 0.008)$

$\rho_{m}=1.00 \mathrm{~g} / \mathrm{cm}^{3}( \pm 0.004)$

$\mu^{\prime}=11.3 \times 10^{-3} \mathrm{~g} / \mathrm{cm} . \mathrm{sec}\left( \pm 0.2 \times 10^{-3}\right)$

data $\left(\rho_{y}, \rho_{m}\right.$ and $\left.\mu^{\prime}\right)$ which were adopted for calculations with Eq. (4) are shown with their levels of significance of $5 \%$ (cf. above the caption of Table 2). Unless otherwise noted, all of the deviations from the mean values of $\rho_{y}, \rho_{m}, \mu^{\prime}, d_{e}$, and $Z$ in the tables of this account indicate respective levels of significance of $5 \%$. The value of $\rho_{y}$ obtained in this study was larger than that of the previous paper (2). 
Regarding the experimental range of $c$ (cf. Table 2), the values of $\beta^{\prime}$ and $\beta^{\prime \prime}$ in Eq. $(3)^{\prime}$ were taken in this case as shown below.

$$
\begin{aligned}
& \beta^{\prime}=1 \cdots 2(=\alpha) \\
& \beta^{\prime \prime}=0
\end{aligned}
$$

The values of $\bar{d}_{e}$ were also determined corresponding to $\alpha=0$ (Stokes law) for reference. Arithmetical averages of equivalent size $\bar{d}_{e}$ in each case of $\alpha$ were compared with those of microscopic determination in Table 2.

Although the values of $\beta^{\prime}(=\alpha)$ cannot be taken definitely in this case, the agreement between the values of $\bar{d}_{e}$ measured directly with a microscope and those determined from the data of settling velocities seems to be satisfactory, especially regarding the case of $\alpha=2$. Since the deviation in $\bar{d}_{e}$ which was estimated from those of $\rho_{y}, \rho_{m}$ and $\mu^{\prime}$ in Table 2 was several percent at most, the agreement mentioned above may not be fortuitous.

\section{Serratia marcescens}

The experimental result is exemplified in Fig. 2, in which $v$ is plotted against $Z$. Since linear relationships between $v$ and $Z$ were apparent, straight lines were assumed through each set of the data points (c: constant) in the figure by the method of least squares. For convenience, the values of $v$ which could be read at the intersections of these straight lines with $Z=10^{3}$ were used for further calculation. The experimental data obtained so far with regard to $v$ are summarized with $c, \rho_{y}, \rho_{m}$ and $\mu^{\prime}$ in Table 3.

The values of $\alpha$ which will be required for calculating the size of the cells with Eq. (4) were determined in this case from the following empirical formula.

$$
\alpha=1+229 c^{3.43}
$$

provided: $0.5>c>0.2$

Eq. (3)" corresponds to a curve which is drawn tentatively through the data points in the previous paper pertaining to spherical particles (designated as $\mathrm{B}$ in the original correlation between $\alpha$ and $c$ ) (1). Since the data points concerned are scattered considerably around Curve B and morever, since the spherical particles which are to be represented by the curve are more than 5 microns in size, discussions, whether the use of Eq. (3)" is appropriate or not in this case, will be needed (see below).

The result of calculations using Eq. (4) with respective data described in Table 3 is shown in the first column of $\bar{d}_{e}$ in the table.

As mentioned earlier, the temperature rise of each suspension during the repeated centrifugation was of the order of $10^{\circ}$ above room temperature, at which the values $\left(\rho_{y}, \rho_{m}\right.$ and $\left.\mu^{\prime}\right)$ were determined experimentally. Assuming that the value of $\mu^{\prime}$ during the sedimentation was decreased by about $18.8 \%$ of that at room temperature (3) and moreover, neglecting the effects of the temperature rise on the values $\left(\rho_{y}\right.$ and $\left.\rho_{m}\right)$, the second column 


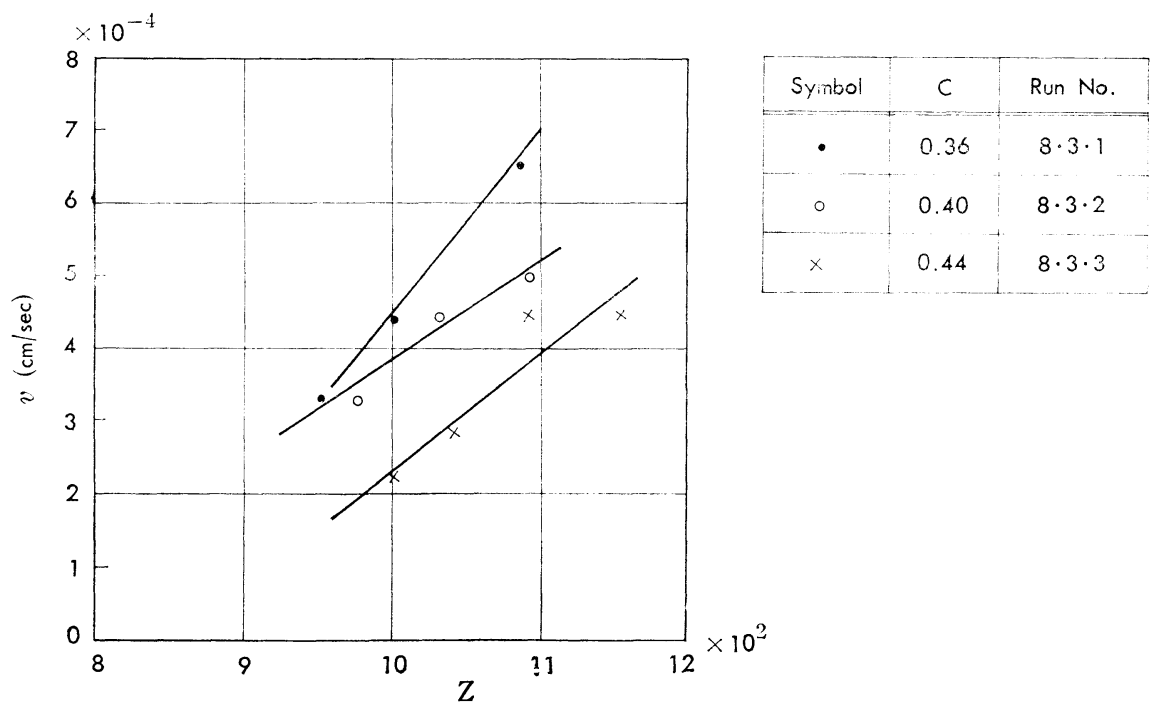

Fig. 2. Rate of subsidence of interface (suspension of Serratia marcescens).

Table 3. Experimental result and calculation.

(Serratia marcescens).

\begin{tabular}{|c|c|c|c|c|c|c|c|c|}
\hline \multirow{3}{*}{ Run No. } & \multirow{3}{*}{$c$} & \multirow{3}{*}{$v(\mathrm{~cm} / \mathrm{sec})$} & \multirow{3}{*}{$\mathrm{V}(\mathrm{cm} / \mathrm{sec})$} & \multirow{2}{*}{\multicolumn{2}{|c|}{$d_{e}$ (microns) }} & \multicolumn{3}{|c|}{$d_{e}$ (microns) } \\
\hline & & & & & & \multicolumn{2}{|c|}{ Calculated } & \multirow{2}{*}{$\begin{array}{c}\text { Observed } \\
\text { microsco } \\
\text { pically }\end{array}$} \\
\hline & & & & $\begin{array}{l}\text { without } \\
\text { correct. }\end{array}$ & $\begin{array}{l}\text { Temp. } \\
\text { correct. }\end{array}$ & $\begin{array}{l}\text { without } \\
\text { correct. }\end{array}$ & $\begin{array}{l}\text { Temp. } \\
\text { correct. }\end{array}$ & \\
\hline $8 \cdot 1 \cdot 1$ & 0.31 & $8.97 \times 10^{-4}$ & $13.00 \times 10^{-4}$ & 1.72 & 1.55 & \multirow{13}{*}{$\begin{array}{l}0 \\
0 \\
+1 \\
+1 \\
\stackrel{-1}{-1}\end{array}$} & \multirow{13}{*}{$\begin{array}{l}-1 \\
\dot{0} \\
+1 \\
10 \\
-1\end{array}$} & \multirow{13}{*}{$\begin{array}{l}0 \\
0 \\
+1 \\
0 \\
-1\end{array}$} \\
\hline $8 \cdot 1 \cdot 2$ & 0.35 & $5.55 \times 10^{-4}$ & $8.54 \times 10^{-4}$ & 1.63 & 1.47 & & & \\
\hline $8 \cdot 1 \cdot 3$ & 0.43 & $4.32 \times 10^{-4}$ & $7.58 \times 10^{-4}$ & 2.09 & 1.88 & & & \\
\hline $8 \cdot 2 \cdot 1$ & 0.37 & $3.78 \times 10^{-4}$ & $6.00 \times 10^{-4}$ & 1.47 & 1.32 & & & \\
\hline $8 \cdot 2 \cdot 2$ & 0.45 & $3.51 \times 10^{-4}$ & $6.38 \times 10^{-4}$ & 2.06 & 1.86 & & & \\
\hline $8 \cdot 3 \cdot 1$ & 0.36 & $4.43 \times 10^{-4}$ & $6.92 \times 10^{-4}$ & 1.52 & 1.37 & & & \\
\hline $8 \cdot 3 \cdot 2$ & 0.40 & $3.86 \times 10^{-4}$ & $6.43 \times 10^{-4}$ & 1.72 & 1.55 & & & \\
\hline $8 \cdot 3 \cdot 3$ & 0.44 & $2.26 \times 10^{-4}$ & $4.04 \times 10^{-4}$ & 1.58 & 1.42 & & & \\
\hline $8 \cdot 8 \cdot 1$ & 0.28 & $9.14 \times 10^{-4}$ & $12.69 \times 10^{-4}$ & 1.51 & 1.36 & & & \\
\hline $8 \cdot 8 \cdot 2$ & 0.31 & $6.99 \times 10^{-4}$ & $10.13 \times 10^{-4}$ & 1.51 & 1.36 & & & \\
\hline $8 \cdot 9 \cdot 1$ & 0.24 & $10.37 \times 10^{-4}$ & $13.64 \times 10^{-4}$ & 1.36 & 1.23 & & & \\
\hline $8 \cdot 9 \cdot 2$ & 0.31 & $7.45 \times 10^{-4}$ & $10.80 \times 10^{-4}$ & 1.57 & 1.41 & & & \\
\hline $8 \cdot 9 \cdot 3$ & 0.36 & $6.76 \times 10^{-4}$ & $10.56 \times 10^{-4}$ & 1.88 & 1.69 & & & \\
\hline
\end{tabular}

$\rho_{y}=1.03 \mathrm{~g} / \mathrm{cm}^{3}( \pm 0.008)$

$\rho_{m}=1.00 \mathrm{~g} / \mathrm{cm}^{3}( \pm 0.001)$

$\mu^{\prime}=8.3 \times 10^{-3} \mathrm{~g} / \mathrm{cm} . \mathrm{sec}\left( \pm 0.3 \times 10^{-3}\right)$

$Z=1000( \pm 20)$ 
of $\bar{d}_{e}$ in Table 3 was prepared, multiplying each value of $\bar{d}_{e}$ in the first column by a factor of $(0.812)^{1 / 2}(=0.901)$.

Evidently the average size determined from the sedimentation velocities is considerably larger than that measured microscopically. Substituting all of the deviations which are noted in Table 3 regarding $\rho_{y}, \rho_{m}, \mu^{\prime}$ and $Z$ into Eq. (4) and at the same time, considering the upper and lower limits of the values of $\alpha$ which can be estimated directly from the scattered data points in the original correlation between $\alpha$ and $c(1)$, the value in the second column of $\bar{d}_{e}$ in the table was ascertained to range from about 2.0 to 1.0 in microns. At any rate, it is considered reasonable to infer that the size determined from the settling velocities was larger than that measured by a conventional means with a microscope.

The reason for this discrepancy between the two values of $d_{e}$ as determined by different procedures will be considered. Designating $n$ as the number of particles (cells) per unit volume of liquid, the volume fraction $c$ is expressed as follows:

$$
\frac{\pi}{6} \bar{d}_{e}^{3} n=c
$$

For simplicity, assuming a cubic arrangement of the particles, the order of magnitude of the distance $l$ between individual particles will be:

$$
l \sim n^{-1 / 3}=\frac{\bar{d}_{e}}{(2 c)^{1 / 3}}
$$

Substituting the experimental range of $c$ (see: Table 3) into Eq. (5),

$$
l \sim \frac{\bar{d}_{e}}{(2 \times 0.45 \sim 2 \times 0.24)^{1 / 3}} \div(1 \sim 1.3) \bar{d}_{e}
$$

Namely, in the sedimentation experiments using the cells of Serratia marcescens, the cell concentration in each suspension was large enough to determine that the distance between the cells was of the same order as the cell size. Thus in suspension, the cells nearly touched each other. In the case of Serratia marcescens, no definite demarcation line of interface was observed in a dilute range of $c$ less than that adopted in this series of experiments. From Table 3, the value of $\bar{d}_{e}$ is seen to depend likely on the value of $c$, the smaller size of $\bar{d}_{e}$ emerging approximately from a lower degree of $c$.

Therefore, the discrepancy between both values of $\bar{d}_{e}$, determined from the settling velocities on one hand and measured with microscope on the other, may indicate that the cells were flocculated to some extent, especially in the case of more concentrated runs in terms of $c$.

In retrospect with the preceding case of yeast cells, the distance $l$ between single particles can also be estimated by substituting the range of $c$ (see: Table 2) into $\mathrm{Eq}(5)$.

$$
l \sim \frac{\bar{d}_{e}}{(2 \times 0.078 \sim 2 \times 0.0052)^{1 / 3}}=(2 \sim 5) \bar{d}_{e}
$$


The cells in suspension are considered to have had less possibilities for flocculation and therefore, the aforementioned agreement between both values of $\bar{d}_{e}$ in Table 2 may be attributed to dispersion of cells during the sedimentation.

At any rate, the determination of equivalent size from the settling velocities seems to be satisfactory so far as the cells which were examined are concerned. This inference entails that the apprehensions in extending the application of the correlation between $\alpha$ and $c(1)$ to the case of particles small enough to be of the order of one micron in size are not presistent and furthermore, that the procedures adopted rather arbitrarily in the determination of the values of $c$ in each case are dependable.

Streptomyces griseus

An example of the experimental data obtained is shown in Fig. 3, from which each value of $c$ was determined as described earlier. The experimental data for short periods of time $t$ in Fig. 3 are reproduced in Fig. 4 for determining the rate of subsidence $v$ of interface.

The data $\left(c\right.$ and $v$ ) secured experimentally are summarized with $\rho_{y}, \rho_{m}$ and $\mu^{\prime}$ in Table 4 .

The values of $\alpha$ were estimated in this case by the following empirical formula.

$$
\alpha=1+305 c^{2.84}
$$

provided: $0.5>c>0.15$

Eq. (3)"' corresponds to Curve A which was drawn tentatively through the data points of the previous study (1) on the correlation between $\alpha$ and $c$ regarding angular as well as flocculated irregular particles. The values of $\alpha$ regarding the case of $c>0.5$ in Table 4 were also estimated from the equation, since this degree of extrapolation does not seem to be serious enough to impair a conclusion of this section. The equivalent size $\bar{d}_{e}$ determined thus far is shown in Table 4. It is noted from the data that the size seems to depend on the value of $c$.

The experimental fact that the values $\left(\rho_{y}\right.$ and $\left.\rho_{m}\right)$ in this case were especially close to each other may lead one to surmise that the spherical bodies which were assumed in the settling of irregular as well as filamentous mycelia of this species might have been composed of or accompanied by a considerable fraction of the liquid medium.

It was apparent from microscopic observations of the suspension that the fibrous mycelia formed, to a certain extent, a sort of network of irregular entity in shape. The mean value $\bar{d}_{e}$ in Table 4 was obtained from microscopic photographs, 20 in total, by measuring and averaging longer and shorter dimensions of each body. Needless to say, the value ( $d_{e}=143$ microns) does not represent any value of $d_{e}$ during the settling in a specific condition of $c$, because the microscopic examination might have changed considerably the dimensions of the respective bodies. However, it is interesting to note from Table 4 that the size $d_{e}$ determined with 


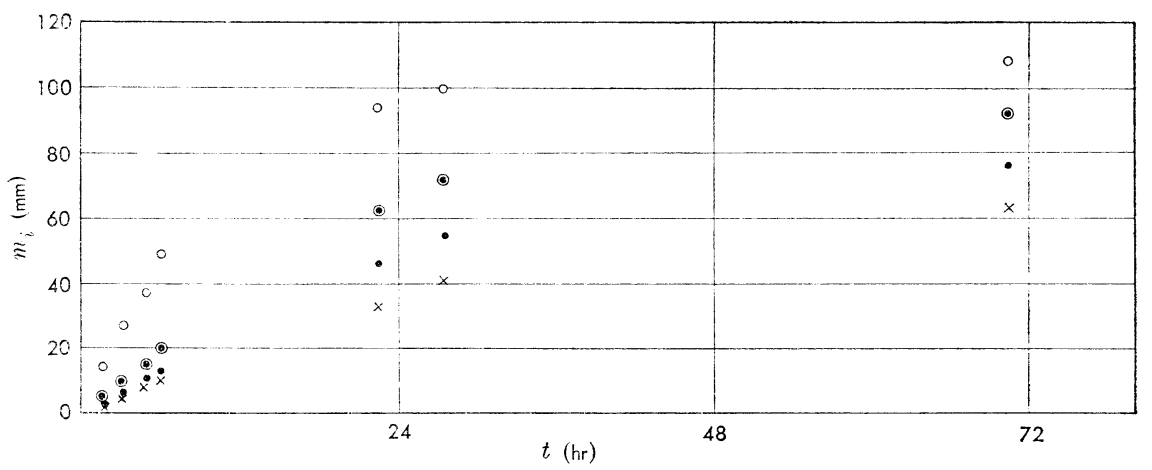

Fig. 3. Determination of volume fraction (Streptomyces griseus).

Table 4. Experimental result and calculation.

(Streptomyces griseus).

\begin{tabular}{|c|c|c|c|c|c|}
\hline Run No. & $c$ & $v(\mathrm{~mm} / \mathrm{hr})$ & $\mathrm{V}(\mathrm{cm} / \mathrm{sec})$ & $d_{e}$ (microns) & $d_{e}$ (microns) \\
\hline $4 \cdot 27 \cdot 1$ & 0.300 & 7.53 & $2.99 \times 10^{-4}$ & 211 & \multirow{13}{*}{ 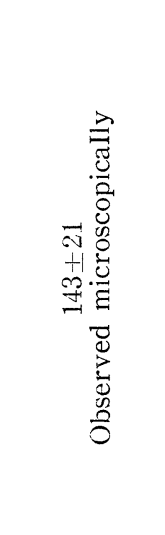 } \\
\hline $4 \cdot 27 \cdot 2$ & 0.388 & 3.33 & $1.52 \times 10^{-4}$ & 213 & \\
\hline $4 \cdot 27 \cdot 3$ & 0.489 & 2.23 & $1.21 \times 10^{-4}$ & 268 & \\
\hline $4 \cdot 27 \cdot 4$ & 0.581 & 1.67 & $1.10 \times 10^{-4}$ & 332 & \\
\hline $5 \cdot 30 \cdot 1$ & 0.215 & 6.93 & $2.46 \times 10^{-4}$ & 131 & \\
\hline $5 \cdot 30 \cdot 2$ & 0.298 & 4.90 & $1.94 \times 10^{-4}$ & 169 & \\
\hline $5 \cdot 30 \cdot 3$ & 0.388 & 3.13 & $1.42 \times 10^{-4}$ & 206 & \\
\hline $5 \cdot 30 \cdot 4$ & 0.532 & 2.33 & $1.39 \times 10^{-4}$ & 326 & \\
\hline $6 \cdot 4 \cdot 1$ & 0.209 & 9.67 & $3.40 \times 10^{-4}$ & 150 & \\
\hline $6 \cdot 4 \cdot 2$ & 0.281 & 5.37 & $2.07 \times 10^{-4}$ & 162 & \\
\hline $6 \cdot 4 \cdot 3$ & 0.353 & 4.47 & $1.92 \times 10^{-4}$ & 210 & \\
\hline $6 \cdot 4 \cdot 4$ & 0.395 & 3.03 & $1.39 \times 10^{-4}$ & 210 & \\
\hline $6 \cdot 4 \cdot 5$ & 0.672 & 0.90 & $0.76 \times 10^{-4}$ & 346 & \\
\hline
\end{tabular}

$\rho_{y}=1.003 \mathrm{~g} / \mathrm{cm}^{3}( \pm 0.0003)$

$\rho_{m}=1.002 \mathrm{~g} / \mathrm{cm}^{3}( \pm 0.0004)$

$\mu^{\prime}=9.7 \times 10^{-3} \mathrm{~g} / \mathrm{cm} . \mathrm{sec}\left( \pm 0.2 \times 10^{-3}\right)$

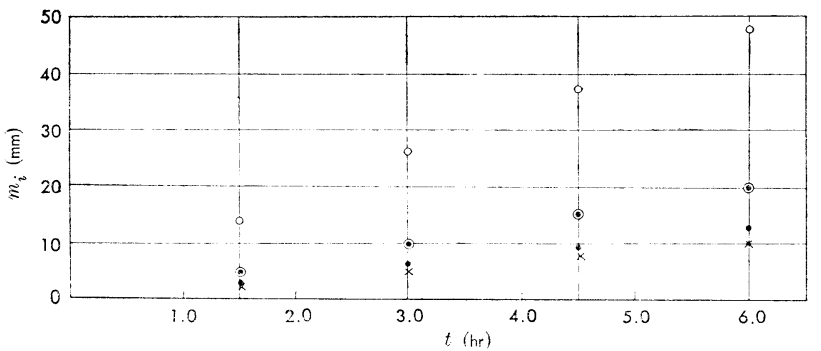

\begin{tabular}{|c|c|c|}
\hline Symbol & $C$ & Run No. \\
\hline 0 & 0.300 & $4 \cdot 27 \cdot 1$ \\
\hline 0 & 0.388 & $4 \cdot 27 \cdot 2$ \\
\hline$\cdot$ & 0.489 & $4 \cdot 27 \cdot 3$ \\
\hline$x$ & 0.581 & $4 \cdot 27 \cdot 4$ \\
\hline
\end{tabular}

Fig. 4. Rate of subsidence of interface (Streptomyces griseus). 
the settling experiment and the size $\bar{d}_{e}$ observed microscopically are of the same order of magnitude, even though the value of $\bar{d}_{e}$ in the former may deviate to the extent of $\pm 50 \%$ in each case depending on the probable fluctuations $\left(\rho_{y}, \rho_{m}, \mu^{\prime}\right.$ and so forth). At any rate, the size $\bar{d}_{e}$ evaluated from the data of the settling experiment may represent the intrinsic size of the mycelial network.

Activated sludge

The experimental data $\left(c, v, \rho_{y}, \rho_{m}\right.$ and $\left.\mu^{\prime}\right)$ obtained are shown in Table 5. Examples of the relation secured between $m_{i}$ and $t$ are shown in

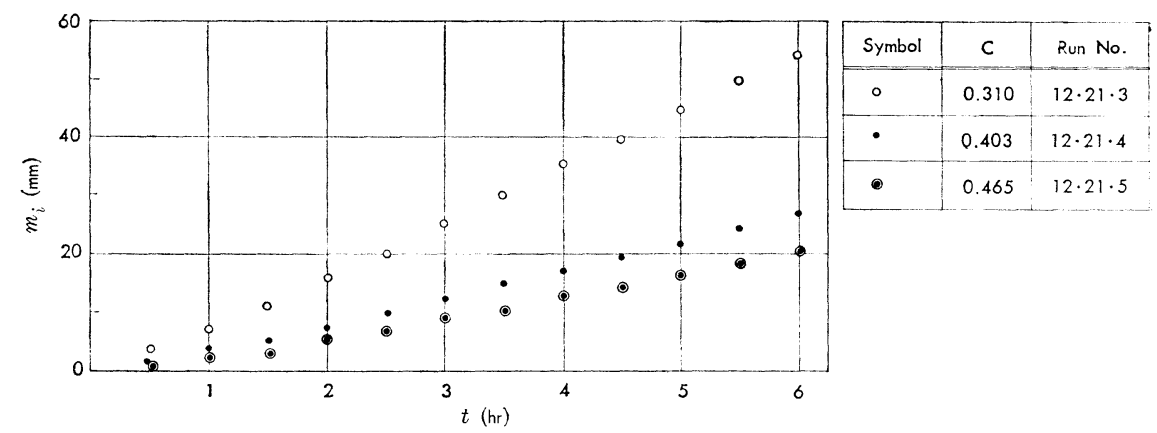

Fig. 5. Rate of subsidence of interface (Activated sludge).

Table 5. Experimental result and calculation.

(Activated sludge).

(Mikawashima Municipal Sewage Treatment Plant, Tokyo).

\begin{tabular}{c|c|c|c|c}
\hline Run No. & $c$ & $v(\mathrm{~mm} / \mathrm{hr})$ & $\mathrm{V}(\mathrm{cm} / \mathrm{sec})$ & $d_{e}$ (microns) \\
\hline $12 \cdot 11 \cdot 1$ & 0.194 & 49.92 & $17.21 \times 10^{-4}$ & 99 \\
$12 \cdot 11 \cdot 2$ & 0.253 & 11.94 & $4.44 \times 10^{-4}$ & 66 \\
$12 \cdot 11 \cdot 3$ & 0.292 & 9.40 & $3.69 \times 10^{-4}$ & 71 \\
$12 \cdot 18 \cdot 1$ & 0.155 & 32.11 & $10.56 \times 10^{-4}$ & 66 \\
$12 \cdot 18 \cdot 2$ & 0.184 & 22.05 & $7.51 \times 10^{-4}$ & 63 \\
$12 \cdot 18 \cdot 3$ & 0.246 & 11.50 & $4.23 \times 10^{-4}$ & 62 \\
$12 \cdot 18 \cdot 4$ & 0.308 & 8.24 & $3.31 \times 10^{-4}$ & 72 \\
$12 \cdot 18 \cdot 5$ & 0.370 & 4.84 & $2.13 \times 10^{-4}$ & 74 \\
$12 \cdot 18 \cdot 6$ & 0.432 & 6.02 & $2.94 \times 10^{-4}$ & 109 \\
$12 \cdot 21 \cdot 1$ & 0.217 & 20.22 & $7.18 \times 10^{-4}$ & 71 \\
$12 \cdot 21 \cdot 2$ & 0.279 & 10.61 & $4.09 \times 10^{-4}$ & 71 \\
$12 \cdot 21 \cdot 3$ & 0.310 & 9.34 & $3.75 \times 10^{-4}$ & 78 \\
$12 \cdot 21 \cdot 4$ & 0.403 & 4.82 & $2.24 \times 10^{-4}$ & 86 \\
$12 \cdot 21 \cdot 5$ & 0.465 & 3.71 & $1.93 \times 10^{-4}$ & 99 \\
\hline$\rho_{y}=1.013 \mathrm{~g} / \mathrm{cm}^{3}( \pm 0.0004)$ & & & \\
$\rho_{m}=1.000 \mathrm{~g} / \mathrm{cm}^{3}( \pm 0.0004)$ & & & \\
$\mu^{\prime}=12.5 \times 10^{-3} \mathrm{~g} / \mathrm{cm} . \mathrm{sec}\left( \pm 0.1 \times 10^{-3}\right)$ & & & \\
\hline
\end{tabular}


Fig. 5, from which each value of $v$ was determined with the method of least squares.

Judging from the procedure described earlier in defining the values of $c$, it may be expected that certain aggregates formed in each mixed liquor are composed of an appreciable fraction of the specific liquid. However, the experimental fact that the value of $\rho_{y}$ in Table 5 is considerably larger than that of Streptomyces griseus (Table 4) may be partly accounted for by that the sludge examined was a complicated assortment of miscellaneous microbes and inorganic substances. The experimental range of $c$ extending from 0.155 to 0.465 was confirmed experimentally to range roughly from $5,200 \mathrm{ppm}$ to $15,500 \mathrm{ppm}$.

The equivalent size $\bar{d}_{e}$ calculated from Equations (3), (4) and $(3)^{\prime \prime \prime}$ is shown in Table 5. It is evident from the table that the dependence of $\bar{d}_{e}$ on $c$ is not so marked compared with the case of Streptomyces griseus (cf. Table 4).

It seems to be difficult to check directly the reliability of the values of $\bar{d}_{e}$ determined thus far from the settling experiment. However, if reasonable agreements mentioned earlier between the values of $\bar{d}_{e}$ determined with the settling experiment and those of $\bar{d}_{e}$ observed microscopically in the case of yeast, bacteria and Actinomyces are taken into account, the data of $\bar{d}_{e}$ in the activated sludge studied can be considered dependable.

\section{SUMMARY}

The empirical formulas reported previously in the prediction of hindered settling velocities of fine particles in suspension were applied to the determination of equivalent size of specific microbial cells in gravitational as well as in centrifugal field. The agreement between the size determined so far from the velocities in hindered settling and that measured directly with a microscope seemed to be satisfactory in the case of yeast cells (Saccharomyces cerevisiae) and bacterial cells (Serratia marcescens) studied. The determination was also made using a strain of Actinomyces (Streptomyces griseus) and an activated sludge, both of which are usually complicated enough in shape compared with bacteria and yeast so that no quantitative studies have ever been made to assess their shape.

If an attempt is made on transfer problems from/to microbial cells, the application of this sort of study will be useful.

\section{NOMENCLATURE}

$c$ : volume fraction of particles (cells)

$\bar{d}_{e}$ : equivalent diameter (cm, microns)

$g$ : acceleration due to gravity $\left(\mathrm{cm} / \mathrm{sec}^{2}\right)$

$l:$ distance between particles $(\mathrm{cm})$

$m_{i}$ : distance of travel of interface $(\mathrm{mm})$ 


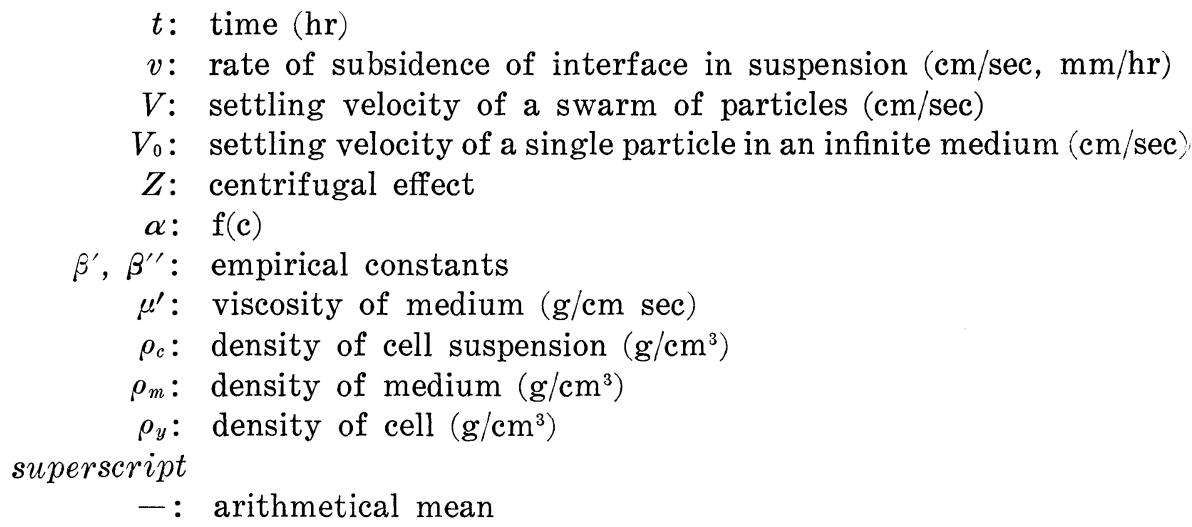

\section{REFERENCES}

(1) S. Aiba., S. Kitai, and N. Ishida: J. Gen. Appl. Microbiol., 8109 (1962).

(2) S. Aiba., S. Kitai, and N. Ishida: ibid., 8, 193 (1962). 